\title{
Ship course stabilization by feedback linearization with adaptive object model
}

\author{
Piotr Borkowski, Ph.D. \\ Maritime University of Szczecin, Poland
}

\begin{abstract}
The algorithm of ship course stabilization herein presented is based on a feedback linearization controller with adaptive object model. The described method, consisting in current approximation of unknown object model functions by neuro-fuzzy approximators, represents a new generation of adaptive control methods. The implementation of this algorithm, which may constitute an executive module of a navigational decision support system, will contribute to a higher degree of automation and navigational safety improvement.
\end{abstract}

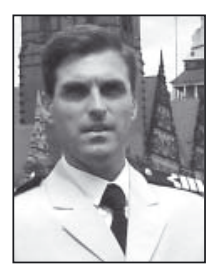

Key words: ship course stabilization; feedback linearization controller; GRBF; safety of navigation

\section{INTRODUCTION}

Cost-effectiveness and constant need for safety enhancement in shipping call for raising the requirements concerning the accuracy of steering a ship for various control tasks. This is particularly true for fairways with heavy traffic and restricted area or depth waters, such as straits and channels, but also for the ship to be conducted along a safe trajectory in the open sea. These situations may be considered as steering along a preset trajectory. Although course stabilization generally seems to be a simple problem of automatic ship control, the fact the object is a complex one (model non-linearity, uncertainty resulting from external disturbances, changing ship's dynamics) makes the task more difficult. One can consider it as an uncertain system, i.e. one in which the object dynamics description is unknown, or only partially known. The functional, or structural, uncertainty calls for current object model adaptation, that is why such systems, called functionally adaptive, represent a new area of intelligent control systems $[4,5,15,16]$.

The author presents an algorithm of ship course stabilization, operating on the basis of a feedback linearization controller [6]. The object model structure is assumed to be partly known. Current approximation of unknown object model functions is achieved by means of neuro-fuzzy approximators based on Gaussian radial basis functions (GRBF) [4].

\section{FEEDBACK LINEARIZATION WITH OBJECT MODEL ADAPTATION}

This chapter is divided into three parts. The first contains a synthesis of the feedback linearization controller, the second part presents a method of object model adaptation, and in the last part the stability of the adaptive system has been proved.

\section{The controller}

Let the dynamics of a continuous object be described by a non-linear equation of state:

where:

$$
\dot{\mathbf{x}}=\mathbf{f}(\mathbf{x}, \mathbf{u})
$$

$\mathbf{f}(\mathbf{x}, \mathbf{u})$ - continuous differentiable vector function, containing zero vectors in its domain,

$\mathbf{x} \quad$ - n-dimensional state vector,

$\dot{\mathbf{x}} \quad-\mathrm{n}$-dimensional vector of state derivatives versus time (t),

u $\quad$ - p-dimensional vector of control signals.

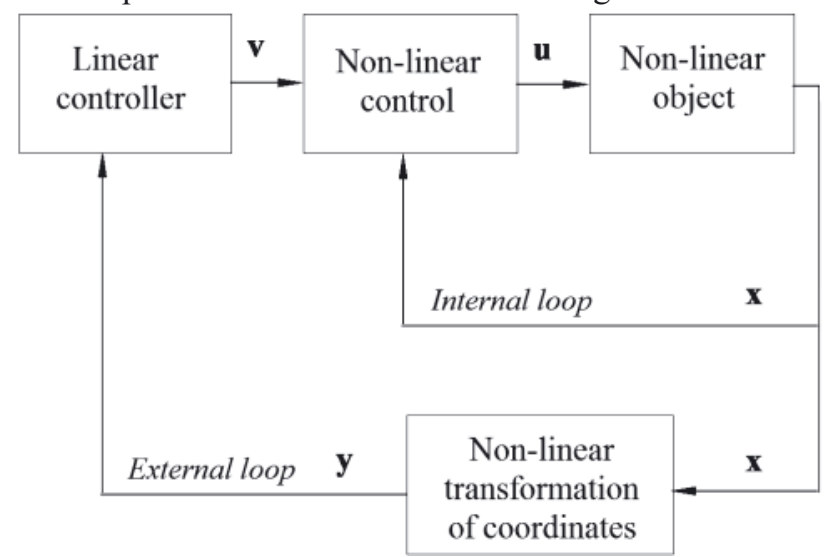

Fig. 1. Architecture of a controller with linearization feedback (source: own study)

The fundamental idea of feedback linearization [6] is illustrated in Fig. 1. It consists in building a non-linear control law $\mathbf{u}$ (assuming the state vector is measurable) as the so called 
internal control loop that linearizes a non-linear system after an appropriate transformation of state space coordinates (from $\mathbf{x}$ to $\mathbf{y}$ ). Then a control $\mathbf{v}$ can be designed in the external loop in new coordinates, making use of the 'rich store' of linear system control methods.

Our considerations will be limited to the class of non-linear single input and affinity systems, due to the form of control signal:

where:

$$
\dot{\mathbf{x}}=\mathbf{f}(\mathbf{x})+\mathbf{g}(\mathbf{x}) \mathrm{u}
$$

$\mathbf{f}(\mathbf{x}), \mathbf{g}(\mathbf{x})$ - smooth vector fields in $\mathrm{R}^{\mathrm{n}}$ (infinitely differentiable functions, with a domain and range $\mathrm{R}^{\mathrm{n}}$ ) and $\mathrm{f}(\mathbf{0})=\mathbf{0}$,

$\mathrm{u}$ - control signal (scalar).

The system described by equation (2) can be linearized by feedback, if there exists a nonlinear control law:

$$
\mathrm{u}=\alpha(\mathbf{x})+\beta(\mathbf{x}) \mathrm{v}
$$

where:

$\alpha(\mathbf{x}), \beta(\mathbf{x})$ - function with a range $\mathrm{R}$ and $\beta(\mathbf{x}) \neq 0$,

$\mathrm{v}$ - new control input (scalar),

and dipheomorphism (differentiable function, whose inverse function exists and is differentiable) transforming the state vector $\mathbf{x}$ into $\mathbf{y}$ :

$$
\mathbf{y}=\mathbf{T}(\mathbf{x})
$$

so that for the control (3) the transformed variables satisfy the linear state equation:

where:

$$
\dot{\mathbf{y}}=\mathbf{A y}+\mathbf{b v}
$$

A - matrix with $\mathrm{n} \times \mathrm{n}$ dimensions, whose elements $\mathrm{a}_{\mathrm{i}, \mathrm{i}=1}$ for $1 \leq \mathrm{i} \leq \mathrm{n}-1$ are equal to one, the others are zeros,

b - n-dimensional vector, whose $\mathrm{n}$-th coordinate is a unity, the others are zeros.

Feedback linearization is called global, if dipheomorphism (4) is determined for any state vector $\mathbf{x}$.

We will now derive a condition for the existence of dipheomorphism (4) and a method of its determination, and the determination of control (3). Differentiating both sides of equation (4) against time, we will obtain:

where:

$$
\dot{\mathbf{y}}=\frac{\partial \mathbf{T}(\mathbf{x})}{\partial \mathbf{x}} \dot{\mathbf{x}}
$$

$\frac{\partial \mathbf{T}(\mathbf{x})}{\partial \mathbf{x}}$ - Jacobian matrix of the transformation $\mathrm{T}(\mathbf{x})$,

which after the application of relation (5) assumes this form:

$$
\frac{\partial \mathbf{T}(\mathbf{x})}{\partial \mathbf{x}} \dot{\mathbf{x}}=\mathbf{A x}+\mathbf{b v}
$$

The above equation can be written as the system:

$$
\begin{gathered}
\frac{\partial \mathrm{T}_{1}(\mathbf{x})}{\partial \mathrm{x}_{1}} \dot{\mathrm{x}}_{1}+\mathrm{K}+\frac{\partial \mathrm{T}_{1}(\mathbf{x})}{\partial \mathrm{x}_{\mathrm{n}}} \dot{\mathrm{x}}_{\mathrm{n}}=\mathrm{T}_{2}(\mathbf{x}) \\
\frac{\partial \mathrm{T}_{2}(\mathbf{x})}{\partial \mathrm{x}_{1}} \dot{\mathrm{x}}_{1}+\mathrm{K}+\frac{\partial \mathrm{T}_{2}(\mathbf{x})}{\partial \mathrm{x}_{\mathrm{n}}} \dot{\mathrm{x}}_{\mathrm{n}}=\mathrm{T}_{3}(\mathbf{x}) \\
\vdots \\
\frac{\partial \mathrm{T}_{\mathrm{n}-1}(\mathbf{x})}{\partial \mathrm{x}_{1}} \dot{\mathrm{x}}_{1}+\mathrm{K}+\frac{\partial \mathrm{T}_{\mathrm{n}-1}(\mathbf{x})}{\partial \mathrm{x}_{\mathrm{n}}} \dot{\mathrm{x}}_{\mathrm{n}}=\mathrm{T}_{\mathrm{n}}(\mathbf{x}) \\
\frac{\partial \mathrm{T}_{\mathrm{n}}(\mathbf{x})}{\partial \mathrm{x}_{1}} \dot{\mathrm{x}}_{1}+\mathrm{K}+\frac{\partial \mathrm{T}_{\mathrm{n}}(\mathbf{x})}{\partial \mathrm{x}_{\mathrm{n}}} \dot{\mathrm{x}}_{\mathrm{n}}=\mathrm{v}
\end{gathered}
$$

that after the introduction of a Lie derivative [7] takes this form:

$$
\begin{gathered}
\mathrm{L}_{\dot{\mathbf{x}}} \mathrm{T}_{1}(\mathbf{x})=\mathrm{T}_{2}(\mathbf{x}) \\
\mathrm{L}_{\dot{\mathbf{x}}} \mathrm{T}_{2}(\mathbf{x})=\mathrm{T}_{3}(\mathbf{x}) \\
\vdots \\
\mathrm{L}_{\dot{\mathbf{x}}} \mathrm{T}_{\mathrm{n}-1}(\mathbf{x})=\mathrm{T}_{\mathrm{n}}(\mathbf{x}) \\
\mathrm{L}_{\dot{\mathbf{x}}} \mathrm{T}_{\mathrm{n}}(\mathbf{x})=\mathrm{v}
\end{gathered}
$$

and accounting for relation (2) and the fact that components: $\mathrm{T}_{2}, \ldots, \mathrm{T}_{\mathrm{n}}$ must be independent of $\mathrm{u}$, contrary to the control $\mathrm{v}$, it will be written as:

$$
\begin{gathered}
\mathrm{L}_{\mathbf{f}(\mathbf{x})} \mathrm{T}_{1}(\mathbf{x})=\mathrm{T}_{2}(\mathbf{x}) \\
\mathrm{L}_{\mathbf{f}(\mathbf{x})} \mathrm{T}_{2}(\mathbf{x})=\mathrm{T}_{3}(\mathbf{x}) \\
\vdots \\
\mathrm{L}_{\mathrm{f}(\mathbf{x})} \mathrm{T}_{\mathrm{n}-1}(\mathbf{x})=\mathrm{T}_{\mathrm{n}}(\mathbf{x}) \\
\mathrm{T}_{\mathrm{n}}(\mathbf{x})+\mathrm{L}_{\mathrm{g}(\mathbf{x})} \mathrm{T}_{\mathrm{n}}(\mathbf{x}) \mathrm{u}=\mathrm{v}
\end{gathered}
$$

At this point one can see that the feedback linearization problem actually requires looking for the component $T_{1}$, as later the remaining components $T_{2}, \ldots, T_{n}$ can be determined inductively from the system (10), then the control input (because $\mathrm{L}_{\mathbf{g}(\mathbf{x})} \mathrm{T}_{\mathrm{n}}(\mathbf{x}) \neq 0$ ):

$$
\mathrm{u}=-\frac{\mathrm{L}_{\mathbf{f}(\mathbf{x})} \mathrm{T}_{\mathrm{n}}(\mathbf{x})}{\mathrm{L}_{\mathrm{g}(\mathbf{x})} \mathrm{T}_{\mathrm{n}}(\mathbf{x})}+\frac{1}{\mathrm{~L}_{\mathrm{g}(\mathbf{x})} \mathrm{T}_{\mathrm{n}}(\mathbf{x})} \mathrm{v}
$$

that for:

$$
\begin{gathered}
\alpha(\mathbf{x})=-\frac{\mathrm{L}_{\mathbf{f}(\mathbf{x})} \mathrm{T}_{\mathrm{n}}(\mathbf{x})}{\mathrm{L}_{\mathrm{g}(\mathbf{x})} \mathrm{T}_{\mathrm{n}}(\mathbf{x})} \\
\beta(\mathbf{x})=\frac{1}{\mathrm{~L}_{\mathrm{g}(\mathbf{x})} \mathrm{T}_{\mathrm{n}}(\mathbf{x})}
\end{gathered}
$$

takes the form (3).

Therefore, how do we determine the component $\mathrm{T}_{1}$ Using the Lie bracket [7] we get:

$$
\begin{gathered}
\mathrm{L}_{\mathrm{ad}_{\mathbf{f}(\mathbf{x})} \mathbf{g}(\mathbf{x})} \mathrm{T}_{1}(\mathbf{x})=\mathrm{L}_{\mathbf{f}(\mathbf{x})} \mathrm{L}_{\mathbf{g}(\mathbf{x})} \mathrm{T}_{1}(\mathbf{x})+ \\
-\mathrm{L}_{\mathbf{g}(\mathbf{x})} \mathrm{L}_{\mathbf{f}(\mathbf{x})} \mathrm{T}_{1}(\mathbf{x})=-\mathrm{L}_{\mathbf{g}(\mathbf{x})} \mathrm{T}_{2}(\mathbf{x})=0
\end{gathered}
$$

and performing the above operations inductively, we obtain a system of partial differential equations versus the component $\mathrm{T}_{1}$ :

$$
\begin{gathered}
\mathrm{L}_{\operatorname{ad}_{\mathbf{f}(\mathbf{x})}^{0} \mathbf{g}(\mathbf{x})} \mathrm{T}_{1}(\mathbf{x})=0 \\
\mathrm{~L}_{\mathrm{ad}_{\mathbf{f}(\mathbf{x})}^{1} \mathbf{g}(\mathbf{x})} \mathrm{T}_{1}(\mathbf{x})=0 \\
\vdots \\
\mathrm{L}_{\mathrm{ad}_{\mathbf{f}(\mathbf{x})}^{\mathrm{n}-2} \mathbf{g}(\mathbf{x})} \mathrm{T}_{1}(\mathbf{x})=0
\end{gathered}
$$

(whose solution yields $\mathrm{T}_{1}$ ) and the relation:

$$
\mathrm{L}_{\mathrm{ad}_{\mathrm{f}(\mathbf{x})}^{\mathrm{n}-1} \mathbf{g}(\mathbf{x})} \mathrm{T}_{1}(\mathbf{x}) \neq 0
$$

thanks to which, by indirect reasoning, we can easily notice that smooth vector fields $\operatorname{ad}_{\mathbf{f}(\mathbf{x})}^{0} \mathbf{g}(\mathbf{x}), \operatorname{ad}_{\mathrm{f}(\mathbf{x})}^{1} \mathbf{g}(\mathbf{x}), \ldots, \operatorname{ad}_{\mathbf{f}(\mathbf{x})}^{\mathrm{n}-1} \mathbf{g}(\mathbf{x})$ must be linearly independent. Therefore, by virtue of Frobenius theorem the system (14) has a solution if and only if the set of vector fields $\left\{\operatorname{ad}_{\mathbf{f}(\mathbf{x})}^{0} \mathbf{g}(\mathbf{x}), \operatorname{ad}_{\mathbf{f}(\mathbf{x})}^{1} \mathbf{g}(\mathbf{x}), \ldots, \operatorname{ad}_{\mathbf{f}(\mathbf{x})}^{\mathrm{n}-2} \mathbf{g}(\mathbf{x})\right\}$ is involutive, which ultimately gives conditions for the existence of dipheomorphism (4). 
The control (3) linearizes the system (2), after the transformation of coordinates (4) and brings it to the form (5), therefore, to obtain asymptotic stability, designing a linear input in the external loop:

$$
\mathrm{v}=-\mathrm{a}_{1} \mathrm{y}_{1}-\ldots-\mathrm{a}_{\mathrm{n}} \mathrm{y}_{\mathrm{n}}
$$

where:

$a_{1}, \ldots, a_{n}$ - positive settings of the controller,

we should select its coefficient in such a manner that the characteristic polynomial (of the created linear system):

$$
\Gamma(s)=s^{n}+a_{n} s^{n-1}+\ldots+a_{2} s+a_{1}
$$

has all roots with negative real part, and for the purpose of the adaptation method we additionally require that at least one pole should have zero imaginary part.

\section{The adaptation}

So far the considerations have referred to a situation where the model (2) is in an overt form. In reality this is not the case, so in the formula for the control law in the internal loop (11) there are unknown functions:

$$
\begin{aligned}
& \alpha_{\mathbf{f}}(\mathbf{x})=\mathrm{L}_{\mathbf{f}(\mathbf{x})} \mathrm{T}_{\mathrm{n}}(\mathbf{x}) \\
& \alpha_{\mathrm{g}}(\mathbf{x})=\mathrm{L}_{\mathrm{g}(\mathbf{x})} \mathrm{T}_{\mathrm{n}}(\mathbf{x})
\end{aligned}
$$

To identify these functions we will use neuro-fuzzy approximators [4]:

$$
\begin{aligned}
& \hat{\alpha}_{\mathbf{f}}(\mathbf{x})=\mathbf{w}_{\mathbf{f}}^{\mathrm{T}} \boldsymbol{\Phi}_{\mathbf{f}}+\alpha_{\mathbf{f} 0}(\mathbf{x}) \\
& \hat{\alpha}_{\mathrm{g}}(\mathbf{x})=\mathbf{w}_{\mathbf{g}}^{\mathrm{T}} \boldsymbol{\Phi}_{\mathrm{g}}+\alpha_{\mathrm{g} 0}(\mathbf{x})
\end{aligned}
$$

where:

$\mathbf{w}_{\mathrm{f}}, \mathbf{w}_{\mathrm{g}} \quad$ - k-dimensional vectors of weight parameters, $\alpha_{\mathrm{f} 0}(\mathbf{x}), \alpha_{\mathrm{g} 0}(\mathbf{x})$ - known initial function estimates (18), $\boldsymbol{\Phi}_{\mathrm{f}}, \boldsymbol{\Phi}_{\mathrm{g}} \quad-$ k-dimensional basis functions,

built on Gaussian radial basis functions (GRBF), whose i-th element has the form $(1 \leq \mathrm{i} \leq \mathrm{k})$ :

$$
\begin{aligned}
& \Phi_{\mathbf{f}_{i}}(\mathbf{x})=\exp \left\{\frac{-\left\|\mathbf{x}-\boldsymbol{\mu}_{\mathbf{f}_{i}}\right\|^{2}}{2 \sigma_{\mathbf{f}}^{2}}\right\} \\
& \Phi_{\mathbf{g}_{i}}(\mathbf{x})=\exp \left\{\frac{-\| \mathbf{x}-\left.\boldsymbol{\mu}_{\mathbf{g}_{i}}\right|^{2}}{2 \sigma_{\mathbf{g}}^{2}}\right\}
\end{aligned}
$$

where:

$\mathbf{u}_{\mathbf{f}_{\mathrm{i}}}, \mathbf{u}_{\mathrm{g}_{\mathrm{i}}}-\mathrm{n}$-dimensional vectors representing centres (symmetry axes) of $i$-th elements of basis functions,

$\sigma_{\mathrm{f}}^{2}, \sigma_{\mathrm{g}}^{2}$ - variances representing the 'width' of basis functions, $\|\mathbf{x}\|$ - Euclidean norm.

The values of weight parameters should change depending on the dynamics error, which due to the fact that the control:

$$
\mathrm{u}=-\frac{\hat{\alpha}_{\mathbf{f}}(\mathbf{x})}{\hat{\alpha}_{\mathbf{g}}(\mathbf{x})}+\frac{1}{\hat{\alpha}_{\mathbf{g}}(\mathbf{x})} \mathrm{v}
$$

generally does not satisfy the last relation of the system (10), should be defined as below (the other equation is created by replacing $\mathbf{v}$ with a term derived from the control (21)):

$$
\begin{gathered}
\mathrm{e}=\alpha_{\mathrm{f}}(\mathbf{x})+\alpha_{\mathrm{g}}(\mathbf{x}) \mathrm{u}-\mathrm{v}= \\
=\alpha_{\mathrm{f}}(\mathbf{x})-\hat{\alpha}_{\mathrm{f}}(\mathbf{x})+\left[\alpha_{\mathrm{g}}(\mathbf{x})-\hat{\alpha}_{\mathrm{g}}(\mathbf{x})\right]
\end{gathered}
$$

and assuming the vector $\mathbf{y}$ is measurable, it can be calculated from the following relation, obtained from the last component of the equation (5) and by putting in (16)):

$$
\begin{aligned}
& e=\dot{y}_{n}-\left(-a_{1} y_{1}-a_{2} y_{2}-K-a_{n} y_{n}\right)= \\
& =y_{1}^{(n)}+a_{n} y_{1}^{(n-1)}+K+a_{2} y_{1}^{(1)}+a_{1} y_{1}
\end{aligned}
$$

If we now apply a Laplace transformation and the notation (17), we get:

$$
\begin{gathered}
\mathrm{e}(\mathrm{s})=\Gamma(\mathrm{s}) \mathrm{y}_{1}(\mathrm{~s})= \\
(\mathrm{s}+\mathrm{d}) \Gamma_{1}(\mathrm{~s}) \mathrm{y}_{1}(\mathrm{~s})=(\mathrm{s}+\mathrm{d}) \mathrm{e}_{1}(\mathrm{~s})
\end{gathered}
$$

where:

d - number opposite to the real root of the polynomial (17),

$\Gamma_{1}(s)$ - polynomial $s^{\mathrm{n}-1}+\mathrm{b}_{\mathrm{n}-1} \mathrm{~s}^{\mathrm{n}-2}+\ldots+\mathrm{b}_{2} \mathrm{~s}+\mathrm{b}_{1}$, created by dividing (17) by $(\mathrm{s}+\mathrm{d})$,

$\mathrm{e}_{1}(\mathrm{~s})$ - filtered dynamics error $\left(\mathrm{e}_{1}(\mathrm{t})=\mathrm{y}_{1}{ }^{(\mathrm{n}-1)}+\mathrm{b}_{\mathrm{n}-1} \mathrm{y}_{1}^{(\mathrm{n}-2)}+\ldots+\right.$ $\left.+\mathrm{b}_{2} \mathrm{y}_{1}^{(1)}+\mathrm{b}_{1} \mathrm{y}_{1}\right)$.

The error $\mathrm{e}_{1}(\mathrm{t})$ will serve for the determination of the adaptation law of network weight parameters:

$$
\dot{\mathbf{w}}_{\mathrm{f}}=\eta_{\mathrm{f}} \mathrm{e}_{1} \boldsymbol{\Phi}_{\mathrm{f}} ; \dot{\mathbf{w}}_{\mathrm{g}}=\eta_{\mathrm{g}} \mathrm{e}_{1} \boldsymbol{\Phi}_{\mathrm{g}} \mathrm{u}
$$

where:

$\eta_{\mathrm{f}}, \eta_{\mathrm{g}}$ - constant coefficients of adaptation.

\section{Stability of the adaptive system}

We will now prove the stability of the adaptive system under consideration. Let $\mathbf{w}_{\mathbf{f}}^{*}, \mathbf{w}_{\mathbf{g}}^{*}$ be full-network vectors of weight parameters, for which these relations hold:

$$
\begin{aligned}
& \alpha_{\mathbf{f}}(\mathbf{x})=\mathbf{w}_{\mathbf{f}}^{* \mathrm{~T}} \boldsymbol{\Phi}_{\mathbf{f}}+\alpha_{\mathbf{f} 0}(\mathbf{x})+\Delta_{\mathbf{f}} \\
& \alpha_{\mathrm{g}}(\mathbf{x})=\mathbf{w}_{\mathrm{g}}^{* \mathrm{~T}} \boldsymbol{\Phi}_{\mathrm{g}}+\alpha_{\mathrm{g} 0}(\mathbf{x})+\Delta_{\mathrm{g}}
\end{aligned}
$$

where $\Delta_{\mathrm{f}}, \Delta_{\mathrm{g}}$ can be regarded as restricted disturbances, and due to their low value they are neglected in practice. Using the relations (22) and (24) and substituting: (19), (26) we get the equation (neglecting: $\Delta_{\mathrm{f}}, \Delta_{\mathrm{g}}$ ):

$$
\dot{\mathrm{e}}_{1}+\mathrm{de}_{1}=\mathbf{w}_{\mathrm{f}}^{* \mathrm{~T}} \boldsymbol{\Phi}_{\mathrm{f}}-\mathbf{w}_{\mathrm{f}}^{\mathrm{T}} \boldsymbol{\Phi}_{\mathrm{f}}+\left(\mathbf{w}_{\mathrm{g}}^{* \mathrm{~T}} \boldsymbol{\Phi}_{\mathrm{g}}-\mathbf{w}_{\mathrm{g}}^{\mathrm{T}} \boldsymbol{\Phi}_{\mathrm{g}}\right) \mathrm{u}
$$

from which we can determine an error derivative $e_{1}$ with respect to time:

$$
\dot{\mathrm{e}}_{1}=-\mathrm{de}_{1}-\widetilde{\mathbf{w}}_{\mathbf{f}}^{\mathrm{T}} \boldsymbol{\Phi}_{\mathrm{f}}-\widetilde{\mathbf{w}}_{\mathrm{g}}^{\mathrm{T}} \boldsymbol{\Phi}_{\mathrm{g}} \mathrm{u}
$$

where:

$$
\begin{aligned}
& \widetilde{w}_{f}^{\mathrm{T}} \Phi_{\mathrm{f}}=\mathbf{w}_{\mathrm{f}}^{\mathrm{T}} \boldsymbol{\Phi}_{\mathrm{f}}-\mathbf{w}_{\mathrm{f}}{ }^{\mathrm{T}} \boldsymbol{\Phi}_{\mathrm{f}} \\
& \widetilde{\mathbf{w}}_{\mathrm{g}}^{\mathrm{T}} \boldsymbol{\Phi}_{\mathrm{g}}=\mathbf{w}_{\mathrm{g}}^{\mathrm{T}} \boldsymbol{\Phi}_{\mathrm{g}}-\mathbf{w}_{\mathrm{g}}{ }^{\mathrm{T}} \boldsymbol{\Phi}_{\mathrm{g}}
\end{aligned}
$$

Let the relation below be a Lyapunov function.

$$
\mathrm{V}\left(\mathrm{e}_{1}\right)=\frac{1}{2} \mathrm{e}_{1}^{2}+\frac{1}{2 \eta_{\mathrm{f}}} \widetilde{\mathbf{w}}_{\mathrm{f}}^{\mathbf{T}} \widetilde{\mathbf{w}}_{\mathrm{f}}+\frac{1}{2 \eta_{\mathrm{g}}} \widetilde{\mathbf{w}}_{\mathbf{g}}^{\mathbf{T}} \widetilde{\mathbf{w}}_{\mathrm{g}}
$$

The time derivative of this function, after substituting the relation (28) has this form:

$$
\begin{gathered}
\dot{\mathrm{V}}\left(\mathrm{e}_{1}\right)=\mathrm{e}_{1} \dot{\mathrm{e}}_{1}+\frac{1}{\eta_{\mathrm{f}}} \widetilde{\mathbf{w}}_{\mathrm{f}}^{\mathrm{T}} \dot{\mathbf{w}}_{\mathrm{f}}+\frac{1}{\eta_{\mathrm{g}}} \widetilde{\mathbf{w}}_{\mathrm{g}}^{\mathrm{T}} \dot{\mathbf{w}}_{\mathrm{g}}= \\
=-\mathrm{de}_{1}^{2}+\widetilde{\mathbf{w}}_{\mathrm{f}}^{\mathrm{T}}\left(\frac{1}{\eta_{\mathrm{f}}} \dot{\mathbf{w}}_{\mathrm{f}}-\mathrm{e}_{1} \boldsymbol{\Phi}_{\mathrm{f}}\right)+\widetilde{\mathbf{w}}_{\mathrm{g}}^{\mathrm{T}}\left(\frac{1}{\eta_{\mathrm{g}}} \dot{\mathbf{w}}_{\mathrm{g}}-\mathrm{e}_{\mathrm{l}} \boldsymbol{\Phi}_{\mathrm{g}} \mathrm{u}\right)^{(30)}
\end{gathered}
$$

and having accounted for the adaptation law of network weight parameters (25) we get for $\mathrm{e}_{1} \neq 0$ : 


$$
\dot{\mathrm{V}}\left(\mathrm{e}_{1}\right)<0
$$

One may conclude from the other Lyapunov's method that the examined adaptive system is asymptotically stable. When we also consider the terms $\Delta_{\mathrm{f}}, \Delta_{\mathrm{g}}$ to obtain asymptotic stability of the system the sliding mode control has to be used [12]. The method consists in adding a properly selected signal to the control, so that the signal guarantees that the inequality (31) holds. We manage to do so here making an additional assumption: $\alpha_{g}(\mathbf{x})>0$ and knowing the constraints of the relation $\Delta_{\mathrm{f}}+\Delta_{\mathrm{g}} \mathrm{u}$, also knowing such number $\mathrm{g}_{\mathrm{sl}}$, for which this relation holds:

$$
\alpha_{\mathrm{g}}(\mathbf{x})>\mathrm{g}_{\mathrm{sl}}>0
$$

In such case, making similar considerations for the control signal in the form:

$$
-\frac{\hat{\alpha}_{\mathbf{f}}(\mathbf{x})}{\hat{\alpha}_{\mathbf{g}}(\mathbf{x})}+\frac{1}{\hat{\alpha}_{\mathbf{g}}(\mathbf{x})} \mathrm{v}-\frac{\operatorname{sign}\left(\mathrm{e}_{1}\right) \cdot \mathrm{o}}{\mathrm{g}_{\mathrm{sl}}}
$$

where:

$\mathrm{o}-$ upper constraint of $\left|\Delta_{\mathrm{f}}+\Delta_{\mathrm{g}} \mathrm{u}\right|$,

we will notice that the inequality (31) will hold, as had to be proven.

\section{SYNTHESIS OF SHIP COURSE STABILIZATION SYSTEM}

Let this equation be a model describing the dynamics of ship movement [8]:

where:

$$
\dot{\mathrm{r}}=-\mathrm{ar}-\mathrm{br}^{3}+\mathrm{c} \delta
$$

$\psi \quad$ - course deviation,

$\mathrm{r}=\dot{\psi}-$ rate of turn,

$\delta$ - rudder angle,

$\mathrm{a}, \mathrm{b}, \mathrm{c}$ - constant coefficients.

Then to harmonize the above with (2) the following notations will be made:

$$
\mathbf{x}=\left[\begin{array}{l}
\psi \\
\mathrm{r}
\end{array}\right] ; \quad \mathrm{u}=\delta ; \quad \mathbf{f}(\mathbf{x})=\left[\begin{array}{c}
\mathrm{r} \\
-\mathrm{ar}-\mathrm{br}^{3}
\end{array}\right] ; \quad \mathbf{g}(\mathbf{x})=\left[\begin{array}{l}
0 \\
\mathrm{c}
\end{array}\right](35)
$$

The control (3) is described by the formula:

$$
\delta=\frac{\mathrm{ar}+\mathrm{br}^{3}}{\mathrm{c}}+\frac{1}{\mathrm{c}} \mathrm{v}
$$

while the dipheomorphism (4) has this form:

$$
\mathbf{y}=\mathbf{T}\left(\left[\begin{array}{l}
\psi \\
\mathrm{r}
\end{array}\right]\right)=\left[\begin{array}{l}
\psi \\
\mathrm{r}
\end{array}\right]
$$

therefore, in this case the feedback linearization is global.

Although the state vector will not be transformed, we already get a linear description of the object:

$$
\begin{aligned}
& \dot{\psi}=\mathrm{r} \\
& \dot{\mathrm{r}}=\mathrm{v}
\end{aligned}
$$

which for:

$$
\mathbf{A}=\left[\begin{array}{ll}
0 & 1 \\
0 & 0
\end{array}\right] ; \quad \mathbf{b}=\left[\begin{array}{l}
0 \\
1
\end{array}\right] ; \quad \mathbf{y}=\left[\begin{array}{l}
\psi \\
\mathrm{r}
\end{array}\right]
$$

will have the form (5).

Coefficients of linear control in the external loop:

$$
\mathrm{v}=-\mathrm{a}_{1} \psi-\mathrm{a}_{2} \mathrm{r}
$$

should be selected so that the characteristic polynomial of the system (38) executing the control (40):

$$
\Gamma(s)=s^{2}+a_{2} s+a_{1}
$$

has two real negative roots.

Now, assuming that the functions

$$
\alpha_{\mathrm{f}}=\mathrm{ar}+\mathrm{br}^{3} ; \alpha_{\mathrm{g}}=\mathrm{c}
$$

are not overtly given, and only their initial estimates are available: $\alpha_{\mathrm{f} 0}, \alpha_{\mathrm{g} 0}$ we will apply neuro-fuzzy approximators (19) to identify the functions. For the approximators, an $\mathrm{i}$-th $(1 \leq \mathrm{i} \leq \mathrm{k})$ element of radial basis functions (20) will have the form:

$$
\begin{aligned}
& \Phi_{\mathbf{f}_{\mathrm{i}}}=\exp \left\{\frac{-\left|\mathrm{r}-\boldsymbol{\mu}_{\mathbf{f}_{\mathrm{i}}}\right|^{2}}{2 \sigma_{\mathbf{f}}^{2}}\right\} \\
& \Phi_{\mathbf{g}_{\mathrm{i}}}=\exp \left\{\frac{-\left|\mathrm{r}-\boldsymbol{\mu}_{\mathbf{g}_{\mathrm{i}}}\right|^{2}}{2 \sigma_{\mathrm{g}}^{2}}\right\}
\end{aligned}
$$

while the adaptation law of weight parameters (25) will be based on the error:

$$
e_{1}=r+\frac{a_{2}-\sqrt{a_{2}^{2}-4 a_{1}}}{2} \psi
$$

An autopilot thus designed guarantees an asymptotic stability of the system on condition that we assume that:

$$
\Delta_{\mathrm{f}} \approx 0 ; \Delta_{\mathrm{g}} \approx 0
$$

Otherwise, to achieve an asymptotic system stability, we have to add a signal to the control, as per the relation (33):

$$
\frac{-\operatorname{sign}\left(e_{1}\right) \cdot o}{g_{s l}}
$$

where:

$\mathrm{g}_{\mathrm{sl}}=0.0005\left[1 / \mathrm{s}^{2}\right]-$ known lower constraint of the function $\alpha_{\mathrm{g}}$.

\section{COMPUTING EXPERIMENTS}

The computing experiments were performed in the Matlab/ Simulink environment. Instead of a ship (real object), a de Witt-Oppe model [3] was used, accounting for the dynamics of the steering gear:

$$
\begin{gathered}
\dot{\mathrm{x}}_{1}=\mathrm{u} \sin \psi+\mathrm{v} \cos \psi \\
\dot{\mathrm{x}}_{2}=\mathrm{u} \cos \psi-\mathrm{v} \sin \psi \\
\dot{\psi}=\mathrm{r} \\
\dot{\mathrm{r}}=-\mathrm{ar}-\mathrm{br}^{3}+\mathrm{c} \delta \\
\dot{\mathrm{u}}=-\mathrm{fu}-\mathrm{Wr}^{2}+\mathrm{S} \\
\mathrm{v}=-\mathrm{r}_{1} \mathrm{r}-\mathrm{r}_{3} \mathrm{r}^{3}
\end{gathered}
$$

where:

$$
\begin{aligned}
\left(\mathrm{x}_{1}, \mathrm{x}_{2}\right)=(\mathrm{x}, \mathrm{y}) \quad & - \text { Cartesian coordinates (ship's position), } \\
\mathrm{u} & - \text { ship's longitudinal speed, } \\
\mathrm{V} & - \text { rate of turn, } \\
\mathrm{S} & - \text { propeller thrust, } \\
\mathrm{a}, \mathrm{b}, \mathrm{c}, \mathrm{f}, \mathrm{W}, \mathrm{r}_{1}, \mathrm{r}_{3}- & \text { coefficients determined from model tests } \\
& \text { (varying for different ship types and } \\
& \text { navigational conditions). }
\end{aligned}
$$

The ship's model coefficients were those of $\mathrm{m} / \mathrm{s}$ Compass Island [3]. To incorporate disturbances, the simulations 

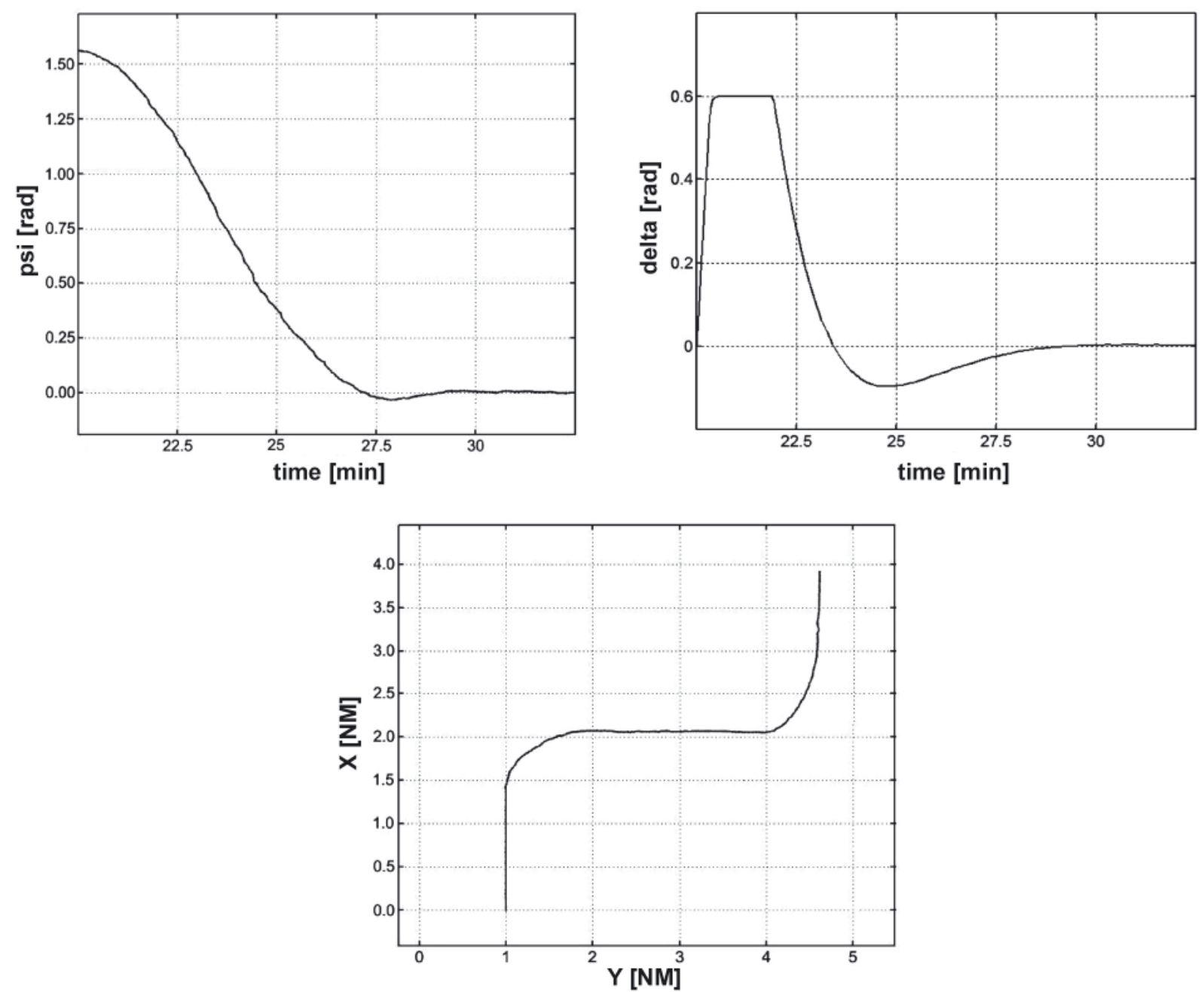

Fig. 2. Course deviations, rudder angle and ship movement trajectory for an example computing experiment (source: own study)

included a signal with characteristics of sea waves generated by wind [2]. The coefficients of linear control in the external loop (40) were determined by means of LQR controller synthesis. One-dimensional radial basis functions (43) were assumed, with zero centres and unit variances. The adaptation law of network weight parameters (25) provides for unit coefficients of adaptation.

Results of an example computing experiment are shown in Fig. 2. The plotted trajectory, rudder angle and changes of course deviations illustrate the ship's successive manoeuvres: course alterations $90^{\circ}$ to starboard, then $90^{\circ}$ to port. The computing experiments confirmed the correct performance of the herein proposed algorithm for ship course stabilization with object model adaptation.

\section{SUMMARY}

The article presents an algorithm of ship course stabilization using object model adaptation based on neuro-fuzzy approximators. The presented method belongs to a new generation of adaptive control methods for uncertain systems.

The algorithm is intended for implementation in the executive module of the navigational decision support system NAVDEC $[9,14]$. The executive and other modules (e.g. data fusion module [1, 13], manoeuvre planning module [11]) make up a practical implementation of navigational decision support system used in the process of safe ship conduct (invention [10]). The implementation of the presented algorithm will lead to higher degree of automation of navigation and enhancement of navigational safety. Consequently, benefits of this development are as follows:

- social benefits due to lower number of human loss of life or health by crews and passengers of sea-going vessels,

- material benefits due to lower losses of cargo, less ship damage and fewer sunken ships,

- environmental protection and prevention of environmental disasters that might result from collisions of ships carrying hazardous materials.

\section{BIBLIOGRAPHY}

1. Borkowski P.: Data fusion in a navigational decision support system on a sea-going vessel. Polish Maritime Research vol. 19, no. 4(76), 78, 2012

2. Borkowski P., Zwierzewicz Z.: Ship course-keeping algorithm based on knowledge base. Intelligent Automation and Soft Computing vol. 17, no. 2, 149, 2011

3. De Wit C., Oppe J.: Optimal collision avoidance in unconfined waters. Journal of the Institute of Navigation, vol. 26, no. 4, 296, 1979

4. Fabri S., Kadirkamanathan V.: Functional adaptive control. Springer, Londyn 2001

5. Farrell J., Polycarpou M.: Adaptive approximation based control. John Wiley, Hoboken 2006

6. Khalil H.: Nonlinear systems. Prentice Hall, Upper Saddle River 2002

7. Marquez H.: Nonlinear control systems. John Wiley, New Jork 2003

8. Perez T.: Ship motion control. Springer, Londyn 2005

9. Pietrzykowski Z., Borkowski P., Wołejsza P.: Marine integrated 
navigational decision support system. Telematics in the transport environment, Communications in Computer and Information Science series no. 329, Springer, Berlin, 284, 2012

10.Pietrzykowski Z., Borkowski P. et al.: A method and system of navigational decision support in the process of safe vessel navigation., International patent application under PCT procedure, no. PCT/PL2010/000112, 08-11-2010

11.Pietrzykowski Z., Magaj J., Wołejsza P., Chomski J.: Fuzzy logic in the navigational decision support process onboard a seagoing vessel. Lecture Notes in Artificial Intelligence series no. 6113, Springer, Berlin, 185, 2010

12.Slotine J.E., Li W.: Applied nonlinear control. Prentice Hall, New Jersey 1991

13.Stateczny A., Kazimierski W.: Determining manoeuvre detection threshold of GRNN filter in the process of tracking in marine navigational radars. Proceedings of the International Radar Symposium, Wrocław, 242, 2008

14.www.navdec.com
15.Zwierzewicz Z.: Nonlinear adaptive tracking-control synthesis for functionally uncertain systems. International Journal of Adaptive Control and Signal Processing vol. 24, no. 2, 96, 2010

16.Zwierzewicz Z.: Ship course-keeping via nonlinear adaptive control synthesis. International Journal of Factory Automation no. $2,102,2007$

\section{CONTACT WITH AUTHOR}

Piotr Borkowski, Ph.D. Institute of Marine Technologies Faculty of Navigation Maritime University of Szczecin Wały Chrobrego 1-2, 70-500 Szczecin, POLAND e-mail: p.borkowski@am.szczecin.pl 